\title{
OK to Proceed? What Every Health Care Provider Should Know About Patient Safety
}

\author{
Keith P. Lewis, Robert J. Canelli, Rafael Ortega (Editors). Boston Medical Centre, MA, \\ USA; 2018, 351 pages. ISBN 9780692186602
}

\author{
Kim E. Turner, BScPhm, MSc, MD, FRCPC
}

Received: 31 January 2019/Accepted: 4 February 2019/Published online: 14 February 2019

(C) Canadian Anesthesiologists' Society 2019

As a profession, anesthesia is recognized as one of the leaders in, and early adopters of, patient safety practices. The term "patient safety" is said to have been coined by the former American Society of Anesthesiologists' President Ellison (Jeep) Pierce who also founded the Anesthesia Patient Safety Foundation (APSF) in 1985, one of the first patient safety organizations ever created. To this day, the APSF continues to work with clinicians, organizations, and industry to improve patient safety surrounding anesthetic care. It was not for another decade and a half that "To Err is Human: Building a Safer Health System" was published revealing that preventable medical errors were responsible for thousands of patient deaths. Healthcare is increasing in complexity with countless opportunities for error. Patient safety is not only a concern for the patients themselves, but also for everyone involved in the healthcare system. Building on this anesthesia legacy, and in recognition of the importance of multidisciplinary care, OK to Proceed? What Every Health Care Provider Should Know About Patient Safety was developed by three anesthesiologists: Keith Lewis, Robert Canelli, and Rafael Ortega. The overall purpose of this work was to equip healthcare providers with a basic knowledge of patient safety and to introduce the "OK to Proceed" model.

This text is written by authors from multiple disciplines, including those not traditionally associated with healthcare, such as lawyers, administrators, and educators. This work recognizes the importance of the different perspectives of

K. E. Turner, BScPhm, MSc, MD, FRCPC ( $\square)$

Departments of Anesthesiology and Perioperative Medicine \& Public Health Sciences, Queen's University, Kingston, ON,

Canada

e-mail: Kim.Turner@kingstonhsc.ca the multidisciplinary authors and understands that patient safety is the responsibility of all members associated with the healthcare team. This also broadens the audience for this text.

The text consists of 52 chapters divided into five sections: Introduction, Known Precipitants of Harm, Strategies to Reduce Error, High Risk Scenarios, and Event Closure. Each chapter incorporates learning objectives, a case study, a discussion, and a summary in the form of "safety pearls". This is an interactive text, with each chapter having two Quick Response codes providing links to both an online case study accompanied by line drawings and an animated summary of some of the key concepts contained within that particular chapter. The text also uses the power of storytelling for learning while the digital enhancements support multiple learning platforms to engage different learning styles. Indeed, this work won an award for Best Instructional Exhibit at the 2017 Post Graduate Assembly of Anesthesiology in New York City. The preface encourages one to use the digital content in the creation of one's own optimal educational presentations.

The chapters within the Introduction deal with some of the underlying concepts in patient safety, including the role of digital media in medical education and introduction of the "OK to Proceed?" model that is also incorporated into many other chapters throughout the text. This model suggests a formalized approach to evaluating the complexity of the clinical scenario $v s$ the level of preparedness required to ensure an appropriate match between the two before proceeding. The section on "Known Precipitants of Harm" includes chapters on diverse topics, including the expected areas of medication errors, procedural sedation, and communication, but it also addresses less mainstream topics such as trainee "burnout" and "time of day". The "Strategies to Reduce Error" 
chapters include cognitive aids and simulation. The shortest section, on "High Risk Scenarios", includes those expected such as surgical fires and difficult airways. Despite the aforementioned three anesthesiologist editors, the chapter on difficult airway was written by two head and neck otolaryngology surgeons and a student. This section yields an interesting evaluation and reminder of the enhanced risks associated with managing a difficult airway outside of the operating room environment. Among suggestions is the placement of a brightly coloured "difficult airway" sticker on the endotracheal tube of those judged to be difficult to intubate in order to enhance communication surrounding the importance of protecting the airway and planning extubation. The final section on "Event Closure" includes debriefing, investigation including equipment sequestration, and root cause analysis in addition to chapters covering less expected perspectives such as "second victims" and "celebrating successes".
This text would appeal to anyone associated with healthcare and interested in a basic introduction to concepts in patient safety and the prevention of adverse events. It would also appeal to educators interested in digital media, storytelling, and wishing to find digital resources to enhance their own teaching of patient safety concepts. Finally, the model as introduced will assist healthcare providers in a more structured approach to their daily analyses of deciding whether it is "OK to Proceed?".

Conflicts of interest None declared.

Editorial responsibility This submission was handled by Dr. Hilary P. Grocott, Editor-in-Chief, Canadian Journal of Anesthesia.

Publisher's Note Springer Nature remains neutral with regard to jurisdictional claims in published maps and institutional affiliations. 